$17^{\text {th }}$ International Congress of Metrology, 11006 (2015)

DOI: $10.1051 /$ metrology $/ 201511006$

(C) Owned by the authors, published by EDP Sciences, 2015

\title{
Some considerations on the use of certified reference materials in the spectrochemical measuring instruments calibration
}

\author{
Steluta Duta ${ }^{1}$ \\ ${ }^{1}$ National Institute of Metrology, 11 Vitan-Barzesti Bucharest, Romania
}

\begin{abstract}
In various measurement areas such as the quality of life and environment monitoring, the public health and food quality, there are performed a large variety of spectrochemical measurement techniques, such as, by molecular spectrometry (UV-VIS), by atomic absorption spectrometry (AAS), by inductively coupled plasma spectrometry (ICP), by optical emission spectrometry (OES), by X-ray spectrometry etc. The metrological calibration of these instruments are instrument'specific. Some related metrological concepts and practical example regarding the linear calibration of the optical emission instruments by using certified reference materials are presented.
\end{abstract}

\begin{abstract}
Résumé: Dans divers domaines de mesure tels que la qualité de vie et de surveillance de l'environnement, la santé publique et la qualité des aliments, il y a une grande variété de spectrochimiques mesures effectué par de spectrométrie moléculaire (UV-VIS), par de spectrométrie d'absorption atomique (AAS), par de spectrométrie à couplage plasma inductif (ICP), par de spectrométrie d'émission optique (OES), par de X-ray spectrométrie etc. L'étalonnage métrologique de ces instruments sont instrument'spécifique. Certains métrologiques connexes et exemples pratique concernant l'étalonnage linéaire des instruments optiques d'émission en utilisant des matériaux de référence sont présentés.
\end{abstract}

\section{Introduction}

It is well known that spectrochemical measurements are performed in the most various areas both concerning the quality of life and environment monitoring, the public health and food quality but also for assigning the materials and processes properties or for the security assurance or work safety. The Certified Reference Materials (MRC) are the chemical standards used to materialize the specific physical-chemical quantities. They are usually used, at least, for the traceability assurance $[1,2]$ of measurement results. The measurement units dissemination and the metrological traceability assurance via the calibration of the measuring instruments according to the SR EN ISO/IEC 17025/2005: "General requirements for the competence of testing and calibration laboratories" must be done in an internationally accepted manner, this means that traceability assurance of measurements results is performed according to the ILAC P10: "Policy on Traceability of Measurement Results". The traceable calibration of the measuring instruments must be performed by "a national metrology institute/designated institute whose service is suitable for the intended use and the service is covered by the CIPM-MRA arrangement". The calibration services provided by a national metrology institute are recognized for the traceability assurance of measurement results if they are based as well on the calibration services provided by " $a$ national metrology institute whose service is suitable for the intended use, even this service is but not covered by the CIPM MRA arrangement, but the metrology institute participates in the relevant CIPM-MRA comparisons for which there are evidences in the Annex $B$ of KCDB of the technical competences for at least one related $C M C$ ". In this context, a lot of efforts are spent in Romania for the instrument calibration to meet the above traceability requirements.

The above considerations are mainly covered in Romania in the field of spectrochemical measurements by instrument calibration with certified reference materials as traceable measurement standards. For instance, in molecular UV-VIS spectrophotometry the absorbance scale calibration is performed with traceable absorbance standards covered by the CIPM-MRA arrangement, and, as a consequence, the traceable concentration values by UV-VIS spectrophotometry could be measured based on Lambert-Beer Law. In atomic absorption spectrometry (AAS) and inductively coupled plasma spectrometry (ICP) if the calibration curve is performed with traceable standard solutions/certified reference materials [3] the first premise for traceability assurance of measurement results is considered.

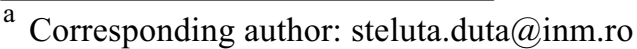


In this paper some metrological aspects are discussed regarding the re-evaluation of the calibration function of the spectral instruments such as the optical emission spectrometers.

\section{Experimental}

The optical emission spectrometers are the instruments that have stored in their software by the manufacturer the calibration model for specific matrices determinations. The coefficients of the calibrations model are also established taking into account the analytical applications of the instruments. The calibration model is normally used without modifications as long as the calibration function is periodically checked and confirmed with certified reference materials with the matrices as much as appropriate as the reference materials initially used by the manufacturer when the calibration model was build. In practice, the user do not spend so much work regarding the calibration model memorised by the software, unless the calibration coefficients and/or correction factors are in acceptable limits and the instrument do not indicate some technical errors.

From metrological point of view the re-evaluation of the linear calibration function is important. The good performance of the instrument at the technical specifications level gives confidence in the measurement results. For this purpose the proposed algorithm is regarding the periodical re-evaluation of the linear calibration function when certified reference materials are used. This algorithm is summarised below. Several assumptions should be considered, such as:

(i) the matrixes of MRC used for evaluation are as closed as possible with the MRC initially used by the manufacturer when the calibration model was build;

(ii) the instrument is technically checked to perform the experiments in the optimal working conditions in accordance with the technical specifications;

Table 1 Experimental data for iron content measurements in aluminium

\begin{tabular}{|c|c|c|c|c|c|c|c|c|c|c|}
\hline \multirow{2}{*}{$\begin{array}{l}\text { MRC } \\
\text { Code }\end{array}$} & \multirow{2}{*}{$\begin{array}{l}\text { Reference } \\
\text { values, } \\
\mathrm{x}_{\mathrm{MRC}}, \mathrm{ppm}\end{array}$} & \multirow{2}{*}{\multicolumn{4}{|c|}{ Individual values, $\mathrm{x}_{\mathrm{m}}, \mathrm{ppm}$}} & \multirow{2}{*}{$\begin{array}{c}\text { Corrected } \\
\text { values, } y_{n}, \\
\text { ppm }\end{array}$} & \multicolumn{4}{|c|}{ Residual values, $\mathrm{e}_{\mathrm{nk}}, \mathrm{ppm}$} \\
\hline & & & & & & & $\mathrm{e}_{\mathrm{n} 1}$ & $e_{n}$ & $\mathrm{e}_{\mathrm{n} 3}$ & $\mathrm{e}_{\mathrm{n} 4}$ \\
\hline 566 & $7.500 \pm 0.500$ & 8.000 & 7.000 & 7.500 & 6.000 & 7.029 & 0.971 & -0.029 & 0.471 & -1.029 \\
\hline 9202 & $13.100 \pm 0.600$ & 13.000 & 14.000 & 11.000 & 12.000 & 12.654 & 0.346 & 1.346 & -1.654 & -0.654 \\
\hline 9203 & $39.700 \pm 0.900$ & 40.000 & 39.000 & 41.000 & 38.000 & 39. & 0.624 & 0.376 & 1.624 & -1.376 \\
\hline 9204 & $88.900 \pm 1.400$ & 89.000 & 90.000 & 88.000 & 88.000 & 89.249 & 0.249 & 0.751 & -1.249 & -1.249 \\
\hline 9205 & $298.000 \pm 3.000$ & 298.000 & 297.000 & 299.000 & 299.000 & 298.865 & -2.865 & -1.865 & 0.135 & 0.135 \\
\hline 579 & $305.000 \pm 6.000$ & 305.000 & 306.000 & 308.000 & 307.000 & 305.897 & 0.103 & 0.103 & 2.103 & 1.103 \\
\hline
\end{tabular}

(iii) the residual errors as the difference of certified reference value and the measured values are constant over the all working range; etc.

\section{Results and discussions}

The experimental work presented in this paper is regarding the evaluation of the linear calibration function of the optical emission spectrometer SPECTROVAC DV4 used for iron content determination in high purity aluminium (99.85-99.99) \%.

The six Certified Reference Materials $(\mathrm{N}=6)$. are used during these experiments; They are PECHINE type and are identified as Code 566; Code 9202 Code 9203; Code 9204; Code 9205 and Code 579. Four number of repeated measurements $(\mathrm{K}=4)$ are performed.

The linear calibration function and its parameters are estimated based on the experimental data obtained by SPECTROVAC DV4 spectrometer from Table 1:

$$
y=-0.506+1.0046 x
$$

The formulas for calculation of the linear calibration parametres (b-slope and a-intercept) are:

$$
b=\frac{N \sum x_{M R C} \cdot x_{m}-\sum x_{m} \sum x_{M R C}}{N \sum x_{M R C}^{2}-\left(\sum x_{M R C}\right)^{2}}
$$

$$
a=\frac{\sum x_{m}-b \sum x_{M R C}}{N}
$$

where $\mathrm{x}_{\mathrm{MRC}}$ is the certified concentration of reference materials and $x_{m}$ is the measured concentration of MRC.

The corrected values $\hat{y}_{n}$ are calculated based on the above calibration function:

$$
\hat{y}_{n}=a+b \cdot x_{M R C}
$$

The residuals $\mathrm{e}_{\mathrm{nk}}$ are calculated as difference between the individual measured values and the corrected values $\hat{y}_{n}$ :

$$
e_{n k}=y_{n k}-y_{n}
$$

with its dispersion $\sigma^{2}$ :

$$
\sigma^{2}=\frac{\sum_{n=1}^{N} \sum_{k=1}^{K}\left(e_{n k}\right)^{2}}{N K-2}
$$

Evaluation of the linear calibration function is carried out from its variability sources using ANOVA evaluation [4]. The variability sources are due to the suitability of the calibration function estimated by $\hat{\sigma}_{l}^{2}$, 
due to the repeatability of measurements ${ }_{\sigma_{p}}{ }^{2}$ and due to the calibration function estimated by $\hat{\sigma}^{2}$. The estimates of these variability sources are based on the sum of squares as presented in Table 2.

The confirmation of the linear calibration function is based on F test; the comparison of dispersion for its homogeneity; the two dispersions compared are (i) the dispersion due to the suitability of the calibration model estimated by ${\hat{\sigma_{l}}}^{2}$ and (ii) the dispersion due to the repeatability of measurement system $\sigma_{p}^{2}$.
$\mathrm{F}_{\text {critic }}$ and $\mathrm{F}_{\text {calculated }}$ are estimated as: $\quad \mathrm{F}_{\text {critic }}=\mathrm{F}_{1-\alpha(\mathrm{N}-2 ; \mathrm{NK}-\mathrm{N})}=$ 2.93 compared with $\mathrm{F}_{\text {calculated }}={ }_{\sigma_{l}}{ }^{2} / \sigma_{p}{ }^{2}=2.14$. As $\mathrm{Fc}_{\text {alculate }}<\mathrm{F}_{\text {critic }}$ the hypothesis of linear calibration model is accepted, as a consequence, the measured value based on the linear calibration function could be corrected, because the linearity hypotheses is correct.

Apart of these considerations, in the meantime, it is important as the measurement system to be under statistical control, so the uper and lower control limits $\left(\mathrm{U}_{\mathrm{d}}\right.$

Table 2: ANOVA calculation for re-evaluation of the calibration function of SPECTROVAC DV4

\begin{tabular}{|c|c|c|c|}
\hline $\begin{array}{l}\text { Variability } \\
\text { Source }\end{array}$ & $\begin{array}{l}\text { Degrees } \\
\quad \text { of } \\
\text { freedom }\end{array}$ & Sum of squares & Dispersions \\
\hline $\begin{array}{l}\text { Linear } \\
\text { calibration } \\
\text { model }\end{array}$ & 1 & $S S T-S S e=\sum_{n=1}^{N} \sum_{k=1}^{K}\left(y_{n k}-\bar{y}\right)^{2}-\sum_{n=1}^{N} \sum_{k=1}^{K}\left(e_{n k}\right)^{2}$ & \\
\hline $\begin{array}{l}\text { Residual } \\
\text { errors }\end{array}$ & $\mathrm{NK}-2=22$ & $S S e=\sum_{n=1}^{N} \sum_{k=1}^{K}\left(e_{n k}\right)^{2}=33.51$ & $\hat{\sigma}^{2}=\frac{S S e}{N K-2}=1.52$ \\
\hline $\begin{array}{l}\text { Suitability of } \\
\text { the calibration } \\
\text { model }\end{array}$ & $\mathrm{N}-2=4$ & $S S e-S S P=\sum_{n=1}^{N} \sum_{k=1}^{K}\left(e_{n k}\right)^{2}-\sum_{n=1}^{N} \sum_{k=1}^{K}\left(y_{n k}-y_{n}\right)^{2}=10.82$ & $\sigma_{l}^{2}=\frac{S S e-S S P}{N-2}=2.70$ \\
\hline $\begin{array}{l}\text { Measurement } \\
\text { repetability }\end{array}$ & $\begin{array}{c}\text { NK-N } \\
=18\end{array}$ & $S S P=\sum_{n=1}^{N} \sum_{k=1}^{K}$ & $\sigma_{p}^{2}=\frac{S S P}{N K-N}=1.26$ \\
\hline $\begin{array}{l}\text { Overall } \\
\text { variability }\end{array}$ & $\mathrm{NK}-1=25$ & $S S T=\sum_{n=1}^{N} \sum_{k=1}^{K}\left(y_{n k}-\bar{y}\right)^{2}$ & \\
\hline
\end{tabular}

and $I_{d}$, respectivelly) of the linear calibration function should be estimated:

$$
\begin{gathered}
U_{d}=\frac{\sigma}{b} t_{1-\xi / 2}(N K-2) \\
\wedge \\
L_{d}=-\frac{\sigma}{b} t_{1-\xi / 2}(N K-2)
\end{gathered}
$$

All the above information regarding the metrological characteristics of the certified reference materials [5] used for the re-evaluation of the calibration function, the linear calibration parametres (b-slope and aintercept) of the re-evaluated calibration, the residuals and its dispersion, the variability due to the suitability of the calibration model and due to the repeatability of measurement system as well as the upper and lower control limits of the linear calibration function should be periodically evaluated and ussually registred in the instrument calibration log-book.
The units dissemination and the metrological traceability assurance via the calibration of the measuring instruments are important issues for comparability of measurement results. For complex matrices analysed by optical emission spectrometry the re-evaluation of the calibration function using certified reference materials is an efficient tool for quality assurance of measurements.

\section{References}

[1] ISO Guide 32:1997: Calibration in analytical chemistry and use of certified reference materials [2] ISO Guide 33:2000: Uses of certified reference materials

[3] ISO Guide $35: 1989 \quad\left(2^{\text {nd }}\right.$ edition $) / 2002 \quad\left(3^{\text {rd }}\right.$ edition)/2006 Certification of reference materials-General and statistical principles

[4] ISO 11095 Project: Étalonnage linéaire utilisant des matériaux de référence, 1993

\section{Conclusions}

